\title{
DA PRIVAÇÃO DA DIGNIDADE SOCIAL À PRIVAÇÃO DA LIBERDADE INDIVIDUAL
}

\author{
Ana Luiza de Souza Castro \\ Pedrinho Guareschi \\ Pontifícia Universidade Católica do Rio Grande do Sul, Porto Alegre, Brasil
}

\begin{abstract}
RESUMO: O presente artigo discute o modo como os adolescentes significam suas práticas de vida e se subjetivam a partir dos contextos da família, da justiça e da medida sócio-educativa de internação, em decorrência de ato infracional cometido. Intenta, assim, questionar a forma como a sociedade e as instituições envolvidas têm tratado a questão. Para tanto, foram realizadas entrevistas com adolescentes considerados autores de atos infracionais que cumpriam a medida de internação na cidade de Porto Alegre, e foi feita a leitura e analisados os conteúdos dos respectivos processos judiciais de execução.
\end{abstract}

PALAVRAS-CHAVE: Adolescentes; ato infracional; subjetividade.

FROM DEPRIVATION OF SOCIAL DIGNITY TO DEPRIVATION OF INDIVIDUAL FREEDOM

ABSTRACT: This paper discusses the way adolescents internalize their life practices and how they recognize and build an image of themselves from the context of their family, the judicial system and the social-educative law enforcement measures of imprisonment that result from infractions perpetrated by them. This study intends to question the way the society and the judicial institutions have been treating this issue. Interviews were conducted with adolescents considered as transgressors, deprived of individual liberty in the city of Porto Alegre/RS. The judicial processes about these adolescents have been read by the author and their content was analyzed and discussed.

KEYWORDS: Adolescents; infractions; subjectivity.

O tema dos adolescentes considerados autores de atos infracionais se configura como um sintoma social contemporâneo. A problemática dos privados de liberdade está na ordem do dia. As rebeliões nas entidades de cumprimento de medidas de internação - as antigas "FEBEMS" (Fundações Estaduais de Bem Estar do Menor) ${ }^{1}-$, os maus tratos nelas sofridos, as mortes, as superlotações e os preconceitos induzem o senso comum a responsabilizar especialmente essa parcela da população pelo aumento da violência urbana no país, pregando, portanto, o rebaixamento da idade penal como instrumento mágico para combatê-la. Essa é uma questão candente que está sempre mais presente no debate nacional, com sérias consequiências sociais e psicológicas. Cremos que esse artigo poderá contribuir em parte para iluminar esse debate.

Os mais diversos, ainda que repetitivos discursos da criminalização da pobreza, da impunidade e da violência dos adolescentes considerados autores de atos infracionais tomam a cena na atualidade. Isso se dá apesar da significativa escassez de estatísticas confiáveis que, de algum modo, confirmem o suposto crescimento de delitos praticados por adolescentes ou, ainda, que estes vêm sendo cometidos com crescente violência e gravidade. Paradoxalmente, a juventude brasileira é a parcela da população que mais sofre e morre em decorrência de situações violentas. De acordo com Waiselfisz (2002), os homicídios são a principal causa de mortalidade juvenil no Brasil. Em estados como Rio de Janeiro, São Paulo e Pernambuco, os homicídios são responsáveis por mais da metade das mortes de jovens. Entendendo o cometimento de um ato infracional como um fato social, ao qual se pode atribuir inúmeras razões, e constatando que poucos estudos partem da análise do discurso desse grupo social, decidiu-se ter, como ponto de partida, a fala dos próprios adolescentes a respeito do delito por eles cometido. Neste sentido, o centro de nossa investigação de pesquisa é examinar quais os efeitos desse ato, nas formas de subjetivação dos adolescentes considerados em conflito com a lei. Para tanto, trataremos a subjetivação enquanto uma produção discursiva do social e da cultura, como modos de ser constituído e estar no mundo, "o processo pelo qual se obtém a constituição de um sujeito, mais exatamente de uma subjetividade, que evidentemente é uma das possibilidades dada de organização de uma consciência de si” (Foucault, 1984, p. 137). 
Neste artigo, examinaremos o modo como os adolescentes significam suas práticas de vida e se subjetivam a partir dos contextos da família, da justiça e da medida sócio-educativa de internação, após o cometimento do ato infracional. Uma das surpresas mais significativas do estudo foi a constatação de que a fala dos adolescentes reproduz, em grande parte, o discurso das instituições, dos juízes e dos técnicos que lidam com eles.

Para entendimento dos termos aqui utilizados, partimos das seguintes definições: ato infracional é compreendido como a conduta descrita como crime ou contravenção penal pela legislação ${ }^{2}$ pela qual o adolescente é julgado e, se considerado culpado, recebe uma medida sócio-educativa, com ou sem privação de liberdade. Família significa as diversas concepções de organização familiar onde há uma relação de cuidado entre um os mais adultos e o adolescente. Como "suporte real, simbólico e imaginário-que um ou mais indivíduo(s) dá a outro para a realização singular da operação de alienação/ separação" (Poli, 2005, p. 200). Por Justiça, entende-se o conjunto de procedimentos institucionais a que o adolescente é submetido após ser acusado de cometer um ato infracional. Nos apoiamos no conceito de práticas judiciárias, forma pela qual, na história ocidental são arbitrados danos e responsabilidades, através da concepção e definição da maneira como os homens podem ser julgados em função dos erros cometidos, como também, a forma pela qual determinados indivíduos podem reparar algumas de suas ações e receber punições por outras (Foucault, 2005). Internação é considerada a medida sócio-educativa mais grave, onde há privação de liberdade, sendo determinada pelo juiz, após um processo legal.

O termo adolescência é tomado sob dupla dimensão: formalmente, como a estabelecida pelo Estatuto da Criança e do Adolescente ([ECA], 1990), isto é, pessoa de doze a dezoito anos, em fase peculiar de desenvolvimento; e numa dimensão psicossocial crítica como um momento significado e interpretado pelo ser humano e sujeito a diferenças culturais e de classes sociais, e não como um período natural de desenvolvimento (Ozella, 2003).

Para dar conta de nosso propósito neste artigo, inicialmente serão apresentadas as notas metodológicas de pesquisa. As informações que servem de fundamento para nosso estudo se constituem de cinco narrativas que sintetizam os conteúdos dos processos judiciais, onde se pode observar como as inúmeras instituições envolvidas com o tema se manifestam a respeito dos adolescentes ${ }^{3}$. Em seguida, mostramos uma única história, montada através das falas dos adolescentes, que, congrega, como narrativa exemplar e paradigmática (Bussoletti, 1997; Ciampa, 1987), a trajetória de vida de vários adolescentes considerados autores de ato infracional. Finalmente, são discutidos os contextos da família, da justiça e da medida sócio-educativa de internação, enquanto modos de significação e subjetivação, espaços privilegiados onde é construída sua subjetividade a partir da problemática do ato infracional.

\section{Notas Metodológicas de Pesquisa}

Como já referido, nesta pesquisa trabalhou-se com cinco adolescentes. A entrevista utilizada foi baseada no conceito de entrevista narrativa (Jovchelovitch \& Bauer, 2002), onde o tema central proposto foi uma narrativa sobre o ato infracional cometido. Em um primeiro momento, tivemos acesso aos Livros de Sentenças dos dois Juizados da Infância e Juventude de Porto Alegre, responsáveis pelos julgamentos de processos de apuração de atos infracionais. Preparou-se, a partir daí, uma listagem com os nomes dos adolescentes que receberam sentenças de internação, sem possibilidade de realização de atividades externas ${ }^{4}$ Selecionando como participantes os adolescentes que não haviam mantido contato anterior com a pesquisadora, que desenvolve suas atividades profissionais no mesmo Juizado da Infância de Juventude de Porto Alegre ${ }^{5}$.

Após a realização das entrevistas, foram estudados os processos judiciais de execução. Optou-se por este tipo de documento em razão de serem os mais completos e compostos por relatórios vindos das unidades onde há privação de liberdade, além de sentenças judiciais, laudos técnicos, inquéritos policiais e promoções do Ministério Público. A parte final consistiu na análise e interpretação das informações, que foram concentradas em três principais blocos, os espaços mais significativos de subjetivação desses adolescentes: a família, a justiça e as instituições de internação.

\section{Cinco Histórias}

André: Já completou dezoito anos. Está privado de liberdade há oito meses, por roubo com uso de arma de fogo. É o único filho de seus pais. Foi criado pela avó paterna desde os três meses de idade. Segundo a mãe, o filho lhe foi "roubado" pela avó paterna e pelo pai. André abandonou a escola quando cursava a quinta série do ensino fundamental. Faz uso de maconha desde os doze anos de idade. De acordo com o Juiz, responsável pela internação provisória: "o adolescente apresenta antecedentes contravencionais, que evidenciam personalidade tendente ao delito". Já o representante do Ministério Público, em sua promoção, solicitou "segregação provisória” para André. Em outra manifestação diz que:

somente pelo fato praticado, já se autoriza o pedido da medida sócio-educativa de internamento, sem possibilidade de realização de atividades externas, única, no entender do Ministério Público, capaz de ter efeito terapêutico e ter o próprio efeito de expiação terapêutica. Outrossim, convém salientar que fatos 
como este tem sido cada vez mais corriqueiros em nossa sociedade, e há que se ter uma postura de exemplo para que esta atividade seja diminuída o mais breve possível.

O laudo psicológico elaborado por psicólogo do Juizado da Infância e Juventude afirma que o jovem "mostra um perfil para estruturação de conduta anti-social, com indicativos para envolvimentos com grau de periculosidade". Refere relatório dos técnicos da FASE, que o adolescente:

denota inteligência, capacidade de reflexão, fica atento e interessado nos atendimentos. Não se compromete, nem mostra arrependimento pela vida que levava. $\mathrm{O}$ envolvimento com drogas, tráfico e assaltos foi profundo. A internação parece se colocar como a primeira barreira intransponível em sua vida.

Novo relatório dá conta de que o adolescente está se beneficiando com a internação: "houve uma reaproximação afetiva do adolescente com a avó, mãe e irmã. Realizou cursos de culinária, além de ter sido aprovado na escola". Em audiência no Juizado, psicóloga da FASE referiu que o adolescente "tem uma identificação com a vida do crime".

Maria: Com dezesseis anos de idade, está privada de liberdade há um ano, por roubo. O pai é usuário de drogas ilícitas e a mãe, de álcool. O casal se separou e um dos irmãos de Maria foi entregue à adoção. $\mathrm{O}$ padrasto é traficante e está preso por latrocínio. A adolescente era agredida por ele. Saiu de casa aos quatorze anos para morar com uma amiga. Fez uso de crack, cocaína e maconha. $\mathrm{O}$ primeiro ato infracional ocorreu no ano de 2001, quando participou de um roubo com emprego de uma faca, a respeito do qual informou à Promotoria que "a irmã está desempregada, bem como a mãe, e precisava comprar leite e fraldas para a irmã de um ano e quatro meses. O pai está preso por latrocínio. O pai só pega dinheiro e gasta em droga". Em audiência no Juizado, a técnica da FASE referiu que "Maria é uma guria muito difícil, tem uma liderança negativa e tendência a reincidir". O Juiz, ao determinar a internação, refere que "a motivação fútil para a prática do ato, bem como o envolvimento em diversos atos infracionais, cristaliza tendência voltada ao anti-social". Abandonou a escola quando cursava a quinta série do ensino fundamental. Refere, em várias de suas audiências, estar sendo atendida em um serviço ambulatorial especializado em adolescentes; cita o nome de sua terapeuta e avalia positivamente o atendimento. De acordo com relatório dos técnicos da FASE: "apresenta comportamento agressivo e desafiador”. No último relatório, é informada a efetivação de uma aproximação entre a adolescente e seus familiares.

Marcelo: Está com dezessete anos de idade. Encontra-se privado de liberdade há quatro meses, por roubo com uso de arma de fogo. Os pais são separados. Era agredido pelo pai. Este, segundo Marcelo, sempre lhe dizia que seria um ladrão. A mãe lhe diz: "não foi esta a criação que eu te dei”. Abandonou a quinta série do ensino fundamental, após várias reprovações. Fazia uso de maconha e crack. De acordo com relatório da FASE, o pai do adolescente maltratava os familiares e acabou por abandoná-los. Durante entrevista com psicóloga do Juizado, Marcelo afirma ter conseguido parar de usar drogas ilícitas, após fazer "uma segurança de umbanda". Refere o Juiz, ao determinar a internação provisória: "tenho como recomendável, por ora, a segregação do adolescente para garantia da ordem pública e da paz social".

João: Com dezesseis anos, está privado de liberdade há dois meses, em decorrência de um roubo. Aos oito anos, presenciou o assassinato do pai que era usuário e traficante de drogas ilícitas. João saiu de casa por não gostar do padrasto, falecido em decorrência do vírus HIV quando se encontrava preso. A mãe e dois irmãos do adolescente também são portadores do vírus. João possui vivências de rua e de abrigamento. Abandonou o colégio após repetir várias vezes a primeira série do ensino fundamental. É usuário de loló. Cometeu vários atos infracionais contra o patrimônio. Refere o Juiz, ao determinar a internação provisória:

no que diz respeito à periculosidade do infrator, esta se demonstra pelo modus operandis e a reiteração criminosa. O infrator é confesso. A internação do infrator é medida que se impõe para garantia de ordem pública e para que, uma vez em liberdade, não volte às ruas para delinqüir.

Pedro: Com quinze anos, está privado de liberdade há quatro meses por roubo com porte de arma. É o único filho do casal, não tendo sido registrado pelo pai. A mãe constituiu uma nova união e teve mais cinco filhos. O padrasto agredia a mãe. O casal encontra-se separado. $\mathrm{O}$ relacionamento entre o padrasto e o adolescente era muito difícil: os dois se agrediam fisicamente. Seu primeiro ato infracional foi porte de maconha e de munição, em agosto de 2004. Abandonou a escola quando cursava a quarta série do ensino fundamental. Durante audiência, Pedro e a mãe relataram agressões físicas sofridas pelo adolescente e desferidas por policiais militares. O juiz determinou a imediata realização de exames no Departamento Médico Legal, para posterior instauração de inquérito e ofício ao Comando da Polícia Militar, objetivando a apuração das agressões relatadas. Sobre a questão, refere a mãe, conforme transcrição da audiência:

eles ameaçaram o meu filho, eu só acho uma coisa assim, nem um menor é santo, tudo que eles fazem eles têm que pagar na justiça né, mas só que uma coisa eu não acho certa, eles, os brigadiano, eles têm que fazer um coisa certa, é pegar o ladrão, se o ladrão é menor, algemar e trazer... mas não agredir o meu filho. 


\section{Decreta o juiz:}

Tenho como recomendável, por ora, a segregação do adolescente, para garantia da ordem pública e da paz social. A liberação do adolescente, pelo menos neste momento, implicaria em risco para a ordem pública, eis que, muito provavelmente, voltaria a praticar atos infracionais, pela sensação de impunidade que sentiria.

O laudo psicológico do Juizado da Infância e Juventude, diz: "há risco de reincidência, o adolescente não conseguiu aproveitar a medida, necessitando de uma contenção e tratamento para drogas".

\section{Muitas numa só História}

A história que segue tem como objetivo apresentar as inúmeras informações colhidas através das entrevistas realizadas num caso exemplar, paradigmático. Achamos útil esse recurso, bastante comum em produções míticas e clássicas, como as narrativas bíblicas de Jó, Abraão, ou o Ulisses da literatura grega, como também em produções científicas (Bussoletti, 1997; Ciampa, 1987). É uma história real que sintetiza a trajetória dos adolescentes que são nosso objeto de estudo:

Quando eu nasci minha mãe falou assim pra minha vó: 'ó mãe: tu me cuida do P.' e ela bem assim: 'eu cuido.' Porque ela não tinha condições quando me ganhô. Por causa que ela queria arrumá um emprego. E todos os meses ela ia lá, ela levava fralda, roupa pra mim. Aí houve um tempo que eu não chamava a minha mãe de mãe. Eu chamava a minha vó de mãe. Chamo até hoje né. Com seis anos ela me pegou de volta. O meu pai não me registró. Quando eu era pequeno ele e a minha mãe brigaram. Ele, o meu pai faleceu no natal, ele era metido e tinha uns contra. Mataram o irmão dele. Aí foi a revolta. Eles entraram atirando. Eu me meti nessa bronca porque eu não gostava do meu padrasto. Ele bebia e chegava chapado em casa. Eu comecei a estudar com oito. Eu ia bem e aí eu rodei por falta. Eu fui expulso da escola. Eu tirei sangue dum colega. A professora aí falou que não me queria mais na sala de aula e me expulsaram. Quebrô o nariz dele, jogando bola. Ele veio correndo, eu dei corpo nele e ele caiu. Trupicou e caiu. A professora pensou que foi de propósito e me tirou. Eu nem gostava daquela professora mesmo. A professora mais chata do colégio era ela. Eu comecei a fumá maconha com quatorze anos porque eu via os outros fumando e eu comecei a fumar também. Eu não sentia nada quando fumava. No início era bom, depois tri ruim porque o cara fica chapado. Vai fazê cinco mês que eu não fumo. Eu parei com a droga. Tinha feito segurança pra largá a droga, um batuque. Peguei um pai de santo e ele fez a segurança e eu parei. Porque droga muda muito o cara. Cega, perde os teus amigo. Ninguém lembra de ti, ninguém quer saber mais de ti. Não quer saber mais do colégio, não quer saber de mais nada. Estraga de vez. E antes de me estragá e antes de eu pegá e me estragá totalmente com a droga, eu resolvi pará e parei. Minha vó qualquer coisinha que eu fazia na rua me botava de castigo. Aí eu cresci revoltado. Quando eu me soltei, me soltei demais. Comecei a usá droga, traficá, roubar. Os guri me convidaram prá assaltá. No fim eu acabei me prendendo sozinho. Perto de onde eu moro que eu me misturo com os guris e vou pro mau caminho. E que eu vi que a minha mãe não tinha condições de né assim cria nós e aí eu fui tentá arrumá um dinheiro. Foi aí que eu comecei me dando mal. Qualquer ladrão, qualquer pessoa que tem um envolvimento com a justiça, só vai pensá depois que tá lá. Na hora que tá na rua, é tudo muito fácil, é tudo muito bom e tudo vem na mão, tudo vem ligeirinho. Não tem como pensá nas consequiências, só quando tá fechado. A minha mãe me avisava e eu nunca acreditava. Ela dizia que era pra mim fazer as coisas certas, estudá, trabalhá e ser alguém na vida. E eu fui preso, aí eu acreditei mesmo. Várias vezes já ela falava pra mim não andá com os guris. Vivia andando e nem dava bola pra ela. Um vez ela pegô e disse: 'um dia tu vai cair na FEBEM e eu não vo ti visitá.' E foi... eu acabei preso. Um ato infracional é cometê coisas fora da lei, é roubá. Como todo adolescente que faz o ato infracional, o cara tem que pagá. Os meus processos são de arrombamento, roubo qualificado, roubo com arma, descuido. Descuido é entrá numa loja e pegá coisa que não é minha. Pegá várias coisas que não são minha, quantidades caras que vão dá bastante prejuízo na loja e de valor que dá bastante dinheiro pra mim. Acho que é grave roubá uma pessoa, botá arma na cara ainda, era marido, mulher e a filha dentro do mercado, mais os cliente. Botá arma na cara de cada um prá pegá dinheiro que eles suam trabalhando pra sustentá. Eu não cumpri o serviço ${ }^{6}$ e aí eles me deram esse ICPAE $^{7}$ pra cumpri, porque eles acharam melhor pra mim. Aí a minha técnica falou pra eu cumpri tudo direitinho pro juiz vê como eu tô bem. ISPAE $^{8}$ eu não entendo direito o que é. Tem umas palavras que eu não entendo. É que o juiz fala muito rápido. Tinha que gravá pra mim escutá o que ele fala. Ele acorda brabo e dá seis meses pra todo mundo. Mas nós não temo culpa se ele tá brabo ou não. Ele tá lá atrás da mesa, só vai dá a sentença, mais ouvi o adolescente, em querê entendê um pouco, ele não entende. Eu tô na FASE porque eu cometi um roubo, porque eu tenho isso daí desde pequeno e eu queria um lugar para melhorá, pra estudá, pra esquecer de tudo. Quando eu saí já vou ter uma nova vida. Mas não aconselho ninguém entrá nessa vida aí. É ruim vive preso todo o dia, junto com aqueles outros guri, só vendo o sol nascê quadrado, não vendo nada, não tá perto da família. Cadeia é cadeia, não existe hotel. Tu não tem como te regenerá lá dentro. Agora que fui isolado, eu só me atrapalhei, agravei meu perfil ${ }^{9}$, o juiz vai lê o meu isolamento e vai querê dá mais seis pro cara. Isolamento é ficá no brete ${ }^{10}$ dormindo sem colchão. E que eu fiz um espanque $^{11}$, dei boas vindas prum cara novato. Mas tô tomando medicação pra dormir, duas vezes por dia, aí o cara não vê o tempo passar. Quando não tava isolado eu estudava de tarde, dormia de manhã e tinha um bom comportamento: não brigava, não desrespeitava os monitor. Mas se essas mulher acham que eu não mudei, 
então eu não vou nunca mudá mesmo. Sabe, eu quero me redimi dos meus pecado. Eu quero cumpri isso para ir pra minha casa, pra mim ajudá a minha mãe, que ela não tem como tomá conta de todos os meus irmão. Falta só eu cumpri essa medida que o juiz me deu e voltá pra casa.

\section{Análise e Interpretação das Informações}

O enorme corpus de informações colhido através das entrevistas e das leituras dos processos judiciais, após várias análises e discussões, pode ser concentrado em três amplos blocos que sintetizam os diferentes espaços onde vivem e lutam esses adolescentes e onde constroem suas trajetórias sofridas: a família, a experiência com a justiça e as instituições de internação. Fazemos uma discussão e interpretação crítica de cada um desses espaços.

\section{A Família: Produtora ou Produto da Exclusão Social?}

A família é uma referência afetiva importante para os adolescentes considerados autores de atos infracionais. Porém, o desemprego, a violência, o uso abusivo de drogas lícitas ou ilícitas, privações de toda ordem e separações de casais são vistos, por esses adolescentes, como fatores do distanciamento familiar. As falas dos adultos cuidadores são escutadas, pelos adolescentes, como sendo o discurso das normas sociais estabelecidas. Assim, entendem a não observância das orientações recebidas como uma das causas do cometimento do delito.

Os adolescentes e seus familiares significam e são subjetivados pelo discurso da mídia, da sociedade contemporânea e do conhecimento dito técnico, os quais depositam na família a causa dos males das crianças e dos jovens. É quase um prognóstico definitivo: família desestruturada ou pais com problemas ocasionarão adolescentes usuários de drogas ilícitas, revoltados, violentos, transgressores e, por fim, autores de atos infracionais. Mas a realidade parece estar um tanto distante de tais afirmativas. Como sugere Assis (1999, p. 55):

A enorme responsabilidade, socialmente atribuída à família, de conduzir a educação dos filhos, associa-se contraditoriamente com a sua falta de controle sobre o jovem, a ponto de não ser capaz de lhe apontar os limites necessários à convivência em sociedade, com os arranjos que tem que fazer para conseguir sobreviver (mudança freqüente de parceiros, tentativa de fuga de relações violentas), ela não pode ser considerada como a única nem a principal responsável pelo envolvimento dos jovens no mundo da infração.

A família sofre, ela também, as conseqüências de relações sociais excludentes. Neste sentido, não deve ser vista como causadora e sim como exposta e subjetivada pelas mesmas situações. O sistema de atendimento e os programas sociais existentes, via de regra, ao invés de intervirem no apoio a essa família, acabam por responsabilizá-la pelas dificuldades do adolescente, colaborando, assim, com o afastamento de seus familiares e o rompimento dos já frágeis vínculos existentes.

Os problemas enfrentados pelos familiares no desempenho dos cuidados frente aos adolescentes parecem, de alguma forma, autorizá-los a buscar o preenchimento dessas graves ausências no cometimento do delito. Tal prática se manifesta nos processos judiciais, onde ainda que indiretamente, há também um julgamento dos adultos cuidadores, responsabilizados, por abandono e negligência, pelo cometimento dos atos infracionais. O que produz um paradoxo: por um lado, em alguns casos, o esforço em reaproximar compulsoriamente ${ }^{12}$ os adolescentes dos familiares; por outro lado, a desvalorização e a culpabilização das famílias. Neste sentido, podemos pensar o cometimento do delito também como uma forma, ainda que às avessas, de recuperar vínculos enfraquecidos entre adolescentes autores de ato infracional e seus familiares. Winnicott (2005) relaciona a separação prolongada de uma criança pequena de sua mãe como um dos fatores externos causadores da delinqüência persistente.

\section{Quem Deve ser Julgado: O Adolescente ou a Justiça?}

As informações obtidas apontam para um grande abismo entre os adolescentes e a Justiça. Evidencia-se uma imensa distância entre os discursos formais dos Juízes e dos adolescentes. Os adolescentes revelam não compreender o que lhes é dito durante as audiências, como também afirmam não se sentirem escutados e compreendidos. A partir dessa constatação, pode-se questionar qual o efeito deste julgamento para os adolescentes, uma vez que estes sequer podem compreender as palavras proferidas pelos Juízes, como nos mostra o depoimento de André:

tem umas palavras que eu não entendo... Ele [o juiz] fala muito. Tinha que gravá pra mim escuta o que ele fala né.... As vezes eu nem sei mais o que ele tá falando, eu não entendo direito o que é ISPAE. Tem umas palavras que eu não entendo.

Como também, nos diz Maria: "Ele [o juiz] fica atrás da mesa, só vai dá a sentença...entendê um pouco, o adolescente, ele não entende".

Em contrapartida, observa-se a aceitação e submissão ao papel normativo representado pela figura de autoridade do Juiz. O ato infracional é visto com um ato "fora da lei", pelo qual o próprio adolescente admite ser penalizado e castigado.

Outro aspecto a ressaltar diz respeito à ausência, nos discursos dos participantes, de qualquer menção aos demais operadores da justiça: técnicos, advogados, pro- 
motores. Ou seja, para os adolescentes, a figura do Juiz parece representar de forma totalizante a Justiça.

O sistema judicial é significado, pelos adolescentes, como algo distante, apartado da sua vida e dos seus sofrimentos. Paradoxo significativo: por um lado, o papel de julgador é aceito e valorizado; por outro lado, é recorrente o pedido, via de regra frustrado, de que o Juiz possa ajudá-los a superar suas dificuldades. Nesse sentido, é de se questionar o efeito da prestação jurisdicional para essa parcela da população, como discute Cunha (2000, p. 52):

a Justiça da Infância e da Juventude herdou o estigma e, em muitos casos, a cultura menorista dos antigos Juizados de Menores, no quais grande parte dos juízes era oriunda dos juízos penais dos adultos, trazendo, portanto, toda a tradição do direito penal. A fusão das culturas menoristas e penalista produziu, numa estranha alquimia, uma prática 'internacionista', na qual a internação de adolescentes se apresenta como principal alternativa a qualquer tipo de problema.

Mais do que a prioridade dada à utilização da medida de internação, a partir da leitura dos processos, observa-se em muitas situações, a construção da periculosidade dos adolescentes, que autoriza a determinação da privação de liberdade. Como refere Foucault (2005) acerca da produção dessa periculosidade, o que ocorre é o julgamento das virtualidades e não dos atos dos indivíduos. Nessa tarefa, observa-se a grande participação dos técnicos, ao legitimarem a responsabilização individual dos adolescentes pelos delitos e ao determinarem uma prognose sobre os riscos de eventuais reiterações infracionais.

A trajetória de vida dos adolescentes considerados autores de atos infracionais é geralmente caracterizada por sucessivas situações reais e subjetivas de exclusão. Ao cometeram um delito, passam a ser sujeitos de garantias e de direitos, fato que sua condição anterior não lhe permitiria. Ao longo desse caminho " melhor seria dizer, desse beco ", o adolescente passa a ter uma identidade social, através do discurso da lei, como infrator, drogado, agressivo, violento, com prognóstico reservado, com periculosidade, com personalidade tendente ao anti-social. Cabe salientar que, no ano de 2005, em vários documentos encontramos, ainda, a palavra menor, símbolo de marcas quase definitivas e difíceis de serem superadas. Como nos disse um adolescente: uma regressão de vida.

Outro fato importante é a constatação de que os adolescentes incorporam o discurso dos técnicos e dos juízes, que com eles trabalham, utilizando os termos e expressões: perfil, isolamento, brete, eu me atrapalhei, assalto a mão armada, certo é estudá, trabalhá ser alguém na vida, sai da vida do crime, minha mãe não tinha condições de me cria.

Tal prática sugere uma espécie de interiorização da linguagem dominante que passa a construir e a fazer par- te do mundo desses adolescentes. Não estamos longe da constatação feita por Freire (1983) de como os grupos dominados introjetam a imagem e os valores dos dominantes, perdendo sua identidade e autonomia.

\section{É Possível Educar Privando a Liberdade?}

Os adolescentes percebem a medida de internação de forma paradoxal. Há, por um lado, a noção de que o afastamento dos supostos problemas poderá ajudar a superá-los, de forma a que possam desempenhar o comportamento esperado pelo Juiz. Por outro lado, os adolescentes considerados autores de ato infracional significam a medida de internação como prisão, manicômio, castigo e segregação, o que fica evidente através das práticas do uso de medicação psiquiátrica como forma de contenção, isolamento como punições a comportamentos considerados inadequados, bem como a falta de atividades e de atendimentos técnicos.

O ECA (1990) define a internação como uma medida sócio-educativa excepcional, somente devendo ser aplicada quando o ato infracional cometido for caracterizado por séria ameaça ou violência à pessoa, quando houver reiteração no cometimento de delitos graves ou por descumprimento de medida determinada anteriormente. Estabelece também que, durante o seu cumprimento, são direitos do adolescente a escolarização e a profissionalização, caracterizando, assim, um paradigma sócio-educativo. No entanto, os adolescentes significam a internação apenas como uma prisão, onde a segregação é a tônica. Ou seja, é possível afirmar que, após dezessete anos de promulgação do ECA, persiste, ainda, o caráter prisional das ações voltadas ao adolescente que comete ato infracional. A falta de atividades, a contenção química, as práticas de isolamento e a quase ausência de atendimentos técnicos apontam para uma situação semelhante à descrita por Tânia Kolker (2002), ao referir os processos de territorializarão e reterriorialização, desenvolvidos inicialmente na década de 1960 por Goffman (1961/1999), quando afirma:

Operando através do isolamento em relação ao exterior, da expropriação dos atributos e valores pessoais, da humilhação e da violação permanente da privacidade, do aniquilamento da autonomia, da submissão a um poder totalitário e da destruição deliberada de qualquer vínculo baseado na solidariedade, essas instituições produziram um tipo peculiar de subjetividade, cuja forma mais acabada poderia ser atingida nas prisões. (p. 89).

É justamente este aniquilamento de qualquer forma de singularidade que a internação parece produzir nos adolescentes. Situação verificada pela própria linguagem dos funcionários das unidades de internação e repetida pelos adolescentes privados de liberdade. Nesse sentido, 
o uso da palavra "brete" é bastante significativo quando buscamos seus sinônimos, segundo o Novo dicionário Aurélio da língua portuguesa (Holanda, 1996, p. 284):

Pequeno curral onde se recolhem as ovelhas para a tosquia; Corredor estreito, um curral, que liga a mangueira à balança e/ ou ao banheiro, e onde se segura a rês para curativo, vacina, marcação, etc; Nas charqueadas e matadouros, corredor estreito onde se abate a rês.

Qualquer das três opções acima referidas nos remete a uma idéia não humana, de perda dessa condição, atributo marcado pelo discurso institucional, aceito e utilizado pelos adolescentes. Partindo do suposto que somos sujeitos de linguagem, constituídos e socializados por ela, é preocupante pensar que o espaço físico destinado aos "sem lugar", é justamente, o da não identidade humana, o da coisificação e o da morte da singularidade.

\section{O Ato Infracional é de Quem?}

O cometimento do ato infracional é o ápice de várias e sucessivas privações, faltas materiais e uma tentativa de pertencimento ao mundo. $\mathrm{O}$ adolescente considerado autor de ato infracional busca sua inclusão na sociedade contemporânea, marcada pelo imperativo do consumo e por relações capitalistas, onde todos podem ser lançados na moda do consumo, porém nem todos podem efetivamente assumir o papel de consumidores (Bauman, 1999). Cometer o delito pode afirmar uma existência até então sem sentido, sem perspectiva de futuro: "eu via tudo mundo com roupa de marca e acabei indo por esse caminho ou a gente quer ser alguém, ter um lugar na sociedade, quer chamar atenção ${ }^{13}$ ".

A exclusão econômica, porém, traz muito mais do que o impedimento de consumo: ser um adolescente brasileiro e pobre significa ser subjetivado pela ausência de perspectivas e de futuro; significa ter como fato cotidiano e concreto a vivência de situações de violência.

Tendo em vista que os mais de dez mil adolescentes privados de liberdade, no Brasil, são na maioria oriundos das camadas pobres da população, percebem-se os processos de exclusão social como um fator de vulnerabilidade para o cometimento e pela responsabilização por atos infracionais. Embora a autoria de delitos não seja, evidentemente, monopólio dos pobres, estes, ao contrário dos incluídos, via de regra, acabam privados de liberdade. Portanto, com nos diz Wacquant (2001) no Brasil, assim como na maioria dos países, a urgência é lutar contra a pobreza e a desigualdade e não contra os criminosos.

A privação de condições de dignidade para os adolescentes e seus familiares, o reconhecimento social que encontram ao cometerem o delito, a justiça que os julga como autores de ato infracional e a segregação da medi- da de internação são formas importantes de socialização que constroem as suas subjetividades. $\mathrm{O}$ ato delinqüente pode ser pensado como uma tentativa de inventar um outro espaço, diverso do espaço cotidiano onde o sujeito adolescente não tem lugar simbolizado (Rassial, 1999).

Podemos ir mais além: o modo como significam os discursos institucionais encontrados nos processos judiciais apontam para uma idéia de serem construídos como de difícil prognóstico, irrecuperáveis, de comportamento agressivo e desafiador. Discursos institucionais que produzem, muitas vezes, o agravamento da situação do adolescente e a determinação da privação de liberdade. É o que se constata na fala de um dos adolescentes entrevistados, ao se referir a uma técnica da unidade de privação, conclui: "se essa mulher acha que eu não mudei, então eu não vou nunca mudá mesmo."

É de extrema preocupação a situação dos adolescentes considerados em conflito com a lei e, mais especificamente, com os privados de liberdade no Brasil. É premente uma política nacional que oriente e fiscalize a aplicação das medidas sócio-educativas, pondo fim, em definitivo, às verdadeiras "prisões juvenis" que grassam no país.

O ECA necessita ser efetivamente implantado. Fazse urgente a implementação das medidas sócio-educativas em meio aberto nos municípios brasileiros, bem como a qualificação dos programas já existentes. A lei precisa ser cumprida; a prioridade no cuidado de crianças e de adolescentes necessita ser bem mais do que uma boa intenção. A medida de internação deve deixar de representar a regra, passando a ser utilizada somente em situações excepcionais, as quais o ECA prevê. Que permaneça, porém, o questionamento: alguma forma de segregação é capaz de trazer benefícios para um ser humano e, particularmente, para um adolescente?

Resta, ainda, a certeza de que o funcionamento e a adequação dos sistemas de atendimento e de justiça para adolescentes considerados autores de ato infracional necessitam ser questionados e transformados. Não há indícios de que trajetórias de vida tão difíceis e repletas de perdas, faltas e privações possam sofrer qualquer forma de mudança sem o respeito à singularidade. Ao contrário, as experiências positivas ocorrem justamente quando são olhados por outros atributos que não o cometimento do delito; quando podem significar outros contextos e se reconhecerem por outros modos de ser e estar no mundo.

\section{Notas}

1. A maioria das fundações do país se adequou, ao menos na nomenclatura, ao Estatuto da Criança e do Adolescente. No estado do Rio Grande do Sul, denomina-se FASE (Fundação de Atendimento Sócio-Educativo).

2. O Estatuto da Criança e do Adolescente - ECA - Lei 8.069, de julho de 1990, artigo 103.

3. Foram utilizados nomes fictícios. 
4. Escolhemos os adolescentes privados de liberdade pela maior gravidade dos delitos, de acordo com o ECA e pela facilidade de localização, tendo em vista os adolescentes se encontrarem institucionalizados.

5. Estamos conscientes que tal fato, somado à circunstância de que os encontros com os adolescentes ocorreram nas dependências do Juizado da Infância e Juventude, poderão ter exercido influência nos relatos, apesar do objetivo das entrevistas e a garantia do sigilo e da não identificação terem sido esclarecidos aos participantes da pesquisa.

6. Medida sócio-educativa de prestação de serviços à comunidade.

7. Medida sócio-educativa de internação com possibilidade de realização de atividades externas.

8. Medida sócio-educativa de internação sem possibilidade de realização de atividades externas.

9. Relatório elaborado pelos técnicos da FASE com o objetivo de sugerir a unidade de internação mais adequada para determinado adolescente.

10. Forma como os monitores se referem ao local onde os adolescentes dormem.

11. Agressões físicas.

12. Via de regra, a existência de um familiar que se responsabilize pelo adolescente é uma condição determinante para sua eventual progressão de medida ou liberação.

13. Falas de jovens recolhidas do documentário gaúcho Becos (Castro, 2003)

\section{Referências}

Assis, S. (1999). Traçando caminhos numa sociedade violenta: A vida de jovens infratores e seus irmãos não infratores. Rio de Janeiro, RJ: Fundação Oswaldo Cruz.

Bauman, Z. (1999). Globalização: As conseqüiências humanas. Rio de Janeiro, RJ: Jorge Zahar.

Bussolletti, D. M. (1997). Mulheres sem terra: Identidade em representação. Dissertação de Mestrado não-publicada, Programa de Pós-Graduação em Psicologia, Pontifícia Universidade Católica do Rio Grande do Sul, Porto Alegre, RS.

Castro, G. (Diretor/Roteirista). (2003). Becos [Vídeo]. Porto Alegre, RS.

Ciampa, A. C. (1987). A estória do Severino e a história da Severina: Um ensaio em Psicologia Social. São Paulo, SP: Brasiliense.

Cunha, J. R. (2000). A lanterna de Diógenes: Considerações sobre a justiça na Justiça. In L. M. T. Brito (Ed.), Jovens em conflito com a lei (pp. 1-162). Rio de Janeiro, RJ: Editora da Universidade do Estado do Rio de Janeiro.

Estatuto da Criança e do Adolescente. (1990). Lei 8.069 de 13 de julho de 1990. Brasília, DF: Conselho Municipal dos Direitos da Criança e do Adolescente.

Foucault, M. (1984). Psicologia e doença mental. Rio de Janeiro, RJ: Tempo Brasileiro.

Foucault, M. (2005). A verdade e as formas jurídicas. Rio de Janeiro, RJ: Nau.

Freire, P. (1983). Pedagogia do oprimido. Rio de Janeiro, RJ: Paz e Terra.

Goffman, E. (1999). Manicômios, prisões e conventos (6. ed.). São Paulo, SP: Perspectiva. (Original publicado em 1961)

Holanda, A. B. (1996). Novo dicionário Aurélio da língua portuguesa. Rio de Janeiro, RJ: Nova Fronteira.

Jovchelovitch, S., \& Bauer, M. W. (2002). Entrevista narrativa. In
M. Bauer \& G. Gaskell (Eds.), Pesquisa qualitativa com texto, imagem e som: Um manual prático. Petrópolis, RJ: Vozes.

Kolker, T. (2002). Tortura nas prisões e produção de subjetividade. In C. Rauter, E. Passos \& R. Benevides (Eds.), Clínica e política: Subjetividade e violação dos direitos humanos. Rio de Janeiro, RJ: TeCorá

Ozella, S. (2003). Adolescências construídas: A visão da psicologia sócio-histórica. São Paulo, SP: Cortez.

Rassial, J. J. (1999). O adolescente e o psicanalista. Rio de Janeiro, RJ: Companhia de Freud.

Poli, M. C. (2005). Clínica da exclusão. São Paulo, SP: Casa do Psicólogo.

Wacquant, L. (2001). As prisões da miséria. Rio de Janeiro, RJ: Jorge Zahar.

Waiselfisz, J. (2002). Mapa da violência III: Os jovens do Brasil: Juventude, violência e cidadania. Brasília, DF: UNESCO.

Winnicott, D. (2005). Deprivación y delincuencia. Buenos Aires, Argentina: Paidós.

Ana Luiza de Souza Castro possui graduação em

Psicologia e mestrado em Psicologia Social pela

Pontifícia Universidade Católica do Rio Grande do Sul (PUCRS). Atualmente atua no Juizado da Infância e Juventude de Porto Alegre. Endereço para correspondência: Tribunal de Justiça do Estado do Rio Grande do Sul, Poder Judiciário do Estado do Rio Grande do Sul, Primeira Vara do Juizado da Infância e da Juventude de Porto Alegre, Rua Marcio Vidor, 10, sala 1006, Cidade Baixa, Porto Alegre, RS. Tel.: (51) 3210

analuizacastro@yahoo.com

Pedrinho Guareschi possui graduação em Filosofia pela Faculdade de Filosofia Imaculada Conceição, graduação em Letras pela Universidade de Passo

Fundo, graduação em Teologia pelo Instituto Redentorista de Estudos Superiores do RS, especialização em Sociologia pela PUCRS, mestrado em Psicologia Social pela Marquette University Milwaudee, doutorado em Psicologia Social pela University Of

Wisconsin At Madison, pós-doutorado pela University of Wisconsin at Madison e pós-doutorado pela University of Cambridge. Atualmente é professor titular da PUCRS. Endereço para correspondência: Pontifícia Universidade Católica do Rio Grande do Sul, Faculdade de Psicologia, Programa de Pós-Graduação em Psicologia, Av. Ipiranga, 6681, Partenon, Porto Alegre, RS, 90619-900. Caixa-Postal: 1429. Tel.: (51) 33203500 ; Ramal: 222; Fax: (51) 33203633. guareschi@pucrs.br

\section{Da Privação da Dignidade Social à Privação da Liberdade Individual} Ana Luiza de Souza Castro e Pedrinho Guareschi Recebido: 27/12/2006

$1^{\text {a }}$ revisão: $27 / 08 / 2007$

$2^{\mathrm{a}}$ revisão: $14 / 09 / 2007$

Aceite final: 26/09/2007 